\title{
POLÍTICAS PÚBLICAS DE ALFABETIZAÇÃO: A BUSCA PELA ERRADICAÇÃO DO ANALFABETISMO NO BRASIL E AS CONCEPÇÕES DE APRENDIZAGEM
}

Public policies on literacy: the search for the eradication of literacy in Brazil and the learning conceptions

\section{Juliana Almeida Gonçalves Fraga}

RESUMO: O artigo traz reflexões a respeito de práticas de alfabetização a partir dos cursos oferecidos pelo governo através das políticas públicas. Analisa os reflexos das formações na prática pedagógica de professores alfabetizadores a partir de observações em uma escola municipal de Porto Alegre. Tem como base teórica: Emília Ferreiro e Ana Teberosky (1984), Ângela Kleiman (1995) e Magda Soares (1990; 2003). Assim como Jean Piaget (1983), pesquisador e autor da epistemologia genética. Contextualiza a alfabetização nas escolas públicas do Brasil, a partir de alguns questionamentos: As políticas públicas de formação de professores têm trazido resultados positivos nas avaliações externas? Como os professores compreendem o desenvolvimento da aprendizagem?

Palavras-chave: Avaliações externas. Formação de professores. Concepções de aprendizagem. Jean Piaget.

ABSTRACT: The article brings reflections on literacy practices from the courses offered by the government through public policies. It analyzes the reflexes of formations in the pedagogical practice of literacy teachers from observations in a municipal school in Porto Alegre. Theoretical basis: Emília Ferreiro and Ana Teberosky (1984), Ângela Kleiman (1995) and Magda Soares (1990; 2003). As well as Jean Piaget (1983), researcher and author of genetic epistemology. It contextualizes literacy in public schools in Brazil, based on some questions: Have public policies for teacher training brought positive results in external evaluations? How do teachers conceive of the development of learning?

Keywords: External assessments. Teacher training. Conceptions of learning. Jean Piaget.

\section{Os investimentos na formação de professores e os resultados das avaliações externas}

É de conhecimento geral que no Brasil há um número significativo de pessoas não alfabetizadas. Mesmo com a ampliação do acesso à educação, o analfabetismo ainda não foi erradicado no Brasil, apesar de ter demonstrado queda nos últimos anos. Os dados do IBGE (Instituto Brasileiro de Geografia e

\footnotetext{
${ }^{\text {I }}$ Pedagoga e Mestra em Educação pela UFRGS, pós-graduada em Alfabetização e letramento pela UNICID, pósgraduada em orientação educacional pela Universidade Cândido Mendes, pós-graduada em Educação Especial pela Universidade Cândido Mendes. Trabalha na SIR. Sala de Inclusão e Recursos.E-mail:profejuzinha@gmail.com.
} 
estatística), mostram que em 2016, 7,2\% da população eram analfabetas, e em 2019, 6,6\%, considerando pessoas com is anos ou mais que não sabem ler nem escrever um bilhete simples. Apesar da melhoria no índice, o país ainda está longe de alcançar a meta de PNE (Plano Nacional de Educação), lei 13.005/2014, que visa erradicar o analfabetismo até 2024 .

Há de se considerar também, os analfabetos funcionais, ou seja, pessoas que escrevem e que decodificam a escrita, mas não têm compreensão do que leem. A pesquisa realizada em 2018 pelo INAF (Índice Nacional de Analfabetismo Funcional), mostra que 30\% da população brasileira é analfabeta funcional.

Os dados revelam que apesar das ações do MEC (Ministério da Educação) em parceria com os estados, municípios e Distrito Federal, nas últimas décadas, a fim de se elevar a qualidade da educação no Brasil, ainda há de se entender e sanar as múltiplas barreiras que impedem a alfabetização total no país.

Dentre as ações do MEC está a ampliação do ensino fundamental de oito para nove anos, consolidado em 2010, a formação continuada de professores e as avaliações externas, que permitem acompanhar o desempenho dos alunos, diagnosticar a aprendizagem e o ensino e traçar metas e estratégias para a melhoria da educação básica.

É notório que quanto mais cedo a criança com plenas capacidades cognitivas tem acesso ao sistema de escrita e vivência com o letramento, mais facilidade terá para se alfabetizar. O governo federal, neste entendimento, implementou o ensino fundamental de nove anos, que se consolidou em 2010. A proposta do MEC é que a criança, que antes se matriculava aos sete anos de idade, passe a frequentar o primeiro ano do ensino fundamental aos seis anos de idade.

A partir de 2013, com a Lei $\mathrm{n}^{\mathrm{O}}$ 12.796/2013, o ensino tornou-se obrigatório a partir dos quatro anos de idade. Esta proposta também tem relação com o PNE, cuja meta era de universalizar o ensino às crianças de quatro anos até 20I6. No entanto, esta meta não foi alcançada.

Neste contexto de baixa alfabetização, há de se considerar a formação de professores como fundamental importância para que a alfabetização ocorra na idade certa. Portanto, o governo federal, em parceria com estados, municípios e DF, tem oferecido inúmeras formações nas últimas décadas.

Em 2004, foi oferecido A Rede Nacional de Formação Continuada de Professores, visando à qualificação dos professores da rede pública do ensino fundamental. Em 2005, o Pró-letramento, em linguagem e em matemática, com duração de oito meses, para professores de anos iniciais do ensino fundamental. O letramento em linguagem tratou de uma proposta de alfabetizar letrando, assim como na área matemática, cujo ensino deve contextualizar as vivências das crianças com os números, relacionando com as funcionalidades do cotidiano. 
Nos anos de 2013 e 2014, professores dos três primeiros anos do ensino fundamental (primeiro ciclo) passaram por uma formação de dois anos, por meio de um curso oferecido pelo governo federal em parceria com os municípios, estados e universidades para a capacitação de professores que trabalham com a alfabetização. O PNAIC (Pacto Nacional pela Alfabetização na Idade Certa) teve como objetivo capacitar os docentes para garantir que todas as crianças até oito anos de idade fossem alfabetizadas, de acordo com a meta cinco do PNE. Até 2024, portanto, 100\% dos estudantes até o final do terceiro ano do ensino fundamental, devem ter a alfabetização consolidada. A adesão ao PNAIC foi por interesse de munícipios e estados brasileiros. No caso de Porto Alegre, todos professores alfabetizadores foram chamados a participar da formação, sendo que a secretaria municipal de educação informou às escolas que os professores que não quisessem participar dessa formação seriam retirados das classes de alfabetização.

No primeiro ano do curso, a ênfase foi o letramento e a alfabetização, enquanto no segundo ano ocorreu a capacitação para o ensino da matemática dos anos iniciais. Formação semelhante ao Próletramento, porém, mais longo e com mais materiais de leitura, bem como suporte de material pedagógico.

Todavia, assim como os dados do IBGE e INAF, a última avaliação ANA (Avaliação Nacional de Alfabetização), que foi aplicada em 2016, cuja criação foi o monitoramento do PNAIC, mostraram que $48 \%$ dos alunos da rede pública alcançaram o esperado em leitura e $42 \%$ em matemática, evidenciando que mais da metade dos alunos do terceiro ano do ensino fundamental tem aprendizagem não consolidada em leitura e interpretação de textos, bem como resolução de problemas matemáticos.

De acordo com Peduzzi (2017), os dados "pelo Instituto Nacional de Estudos e Pesquisas Educacionais Anísio Teixeira (Inep) apontam que a alfabetização estagnou entre 2014 e 2016, mesmo após o PNAIC, curso extenso e com suporte aos professores. Para tentar reverter esse quadro, a secretaria de alfabetização do MEC apresentou medidas da Política Nacional de Alfabetização (PNA), que foi apresentado em 2019, mesmo ano em que a ANA deixou de existir e todas as avaliações externas passaram a ser identificadas como SAEB (Sistema de Avaliação da Educação Básica).

A nova avaliação do Saeb a partir de 2019 é divulgada por nove escalas de proficiência, sendo Nível abaixo de i: Desempenho menor que 650; Nível I: Desempenho maior ou igual a 650 e menor que 675; Nível 8: Desempenho maior ou igual a 825. A matriz de referência do teste foi com base na BNCC (Base Nacional Comum Curricular), de 2017, cujo documento aponta o conteúdo mínimo que deve ser aprendido em cada etapa do ensino, e que todas as crianças sejam alfabetizadas até o segundo ano do ensino fundamental, aos sete anos. Pelo PNE, é até o terceiro ano do ensino fundamental, aos oito anos de idade. 
Os resultados desta avaliação em linguagem apontam que

Cerca de $55 \%$ dos estudantes do $2^{\circ}$ ano do ensino fundamental encontram-se nos níveis 5 a 8 de proficiência em língua portuguesa, de acordo com as escalas do Sistema de Avaliação da Educação Básica (Saeb). [...] a avaliação revela que a maior parte dos estudantes $(21,55 \%)$ concentra-se no nível 5. Por outro lado, 4,62\% dos alunos estão abaixo do nível i, o que indica a provável falta de domínio no conjunto das habilidades que compuseram o teste por parte desses participantes. Em contraponto, 5,04\% dos estudantes estão no nível 8 - um indicativo do domínio da maioria das habilidades testadas. (INEP, 2020).

O nível 5, onde encontram-se a maioria dos estudantes, as prováveis habilidades são localizar as informações explícitas em textos de quatro a seis linhas, interpretar uma tirinha e escrever ortograficamente palavras trissílabas a partir de ditados. No nível 8, onde encontram-se apenas 5,04\% dos estudantes, é que possivelmente estão os capazes de inferir informação e assuntos de textos longos, o que todos ao final do terceiro ano deveriam saber de acordo com o PNE.

O Decreto № 9.765, de II de abril de 2019, que Institui a Política Nacional de Alfabetização, esclarece que

Fica instituída a Política Nacional de Alfabetização, por meio da qual a União, em colaboração com os Estados, o Distrito Federal e os Municípios, implementará programas e ações voltados à promoção da alfabetização baseada em evidências científicas, com a finalidade de melhorar a qualidade da alfabetização no território nacional e de combater o analfabetismo absoluto e o analfabetismo funcional, no âmbito das diferentes etapas e modalidades da educação básica e da educação não formal. (ARTIGOi).

Em consonância com o PNA, a Secretaria de Alfabetização do MEC, estruturou uma nova formação de professores, onde o orçamento é mais de $\mathrm{R} \$ 220$ milhões - O Tempo de Aprender, é por meio de adesão dos estados, municípios e Distrito Federal. Até novembro de 2020 78,69\% dos municípios aderiram ao programa e 74,07\% das UF's, não sendo obrigatório aos professores alfabetizadores. A adesão foi aberta de março de 2020 a janeiro de 2021. (SEALF/MEC, 2020).

A Secretaria Municipal de Porto Alegre, enviou um e-mail convidando os professores a se inscreverem na formação. Não foi percebido muita divulgação por parte da mantenedora em capacitar os alfabetizadores das escolas municipais. O programa Tempo de Aprender tem como objetivo a formação continuada de professores, que iniciou em março de 2020. O curso, totalmente online, capacita principalmente professores, coordenadores pedagógicos, diretores escolares e assistentes de alfabetização. O curso inicial com duração de 3oh, apresenta estratégias de ensino, baseadas em evidências científicas, sobretudo de práticas que mostraram bons resultados em Portugal. Em janeiro de 2021, o programa lançou 
mais um curso online de $18 \mathrm{oh}$, que tem como um dos objetivos, "Promover o uso de métodos de ensino de leitura e escrita eficazes e baseados nas evidências científicas" 2

Como apoio pedagógico os professores contarão com o Sistema On-line de Recursos para Alfabetização (Sora), desenvolvido pela UFG (Universidade Federal de Goiás), tendo um custo de 300 mil reais. Será feito, ainda, o aprimoramento das avaliações e a valorização dos profissionais da alfabetização.

O PNA é recente, não podendo, ainda, se analisar os impactos nas práticas de alfabetização e resultados avaliativos externos, porém, o presente artigo trará reflexões da formação mais extensa que se teve nos últimos anos, o PNAIC. Observou-se práticas de alfabetização de professores em uma escola pública municipal, a partir de alguns questionamentos: O PNAIC alcançou os objetivos na formação de professores alfabetizadores? Trouxe impactos positivos no que se refere a mudanças ou melhorias nos métodos de ensinos? Como entende-se o processo de aquisição da leitura e escrita? O que é necessário à aprendizagem? O PNA, baseado na ciência e evidências na prática, mudará os resultados avaliativos da alfabetização?

$\mathrm{Na}$ formação do PNAIC, houve exigência da participação dos professores, e vale lembrar, ainda, que os cursistas receberam uma bolsa de 200 reais por mês, durante a vigência dos dois anos do curso, que foi presencialmente em sua maior carga horária. O orientador de estudo recebeu $\mathrm{R} \$ 765,00$, assim como o coordenador das ações. $O$ formador da instituição de ensino superior $\mathrm{R} \$$ I.Ioo,oo e o supervisor da instituição de ensino superior $\mathrm{R}$ \$.200,oo. Para o coordenador adjunto da instituição de ensino superior foram $R \$$ I.40o,oo; e $R \$ 2.000$,oo para o coordenador-geral da instituição de ensino superior. $O A B C$, totalmente online, pode também ser acessado por coordenadores pedagógicos, pais dos alunos, e a quem interessar. Não há obrigatoriedade da formação, nem se tem pagamento aos cursistas.

Embora de acordo com a Lei de Diretrizes e Bases da Educação Nacional (LDB), de 1996, recomenda-se que para trabalhar na educação básica é necessária formação em nível superior, que aliás, é uma meta do PNE, ainda tem concurso público para educação infantil e anos iniciais, aceitando somente o curso normal (magistério).

Ora, se os professores da educação básica precisam ter como requisito mínimo o curso normal, ou licenciatura, supõe-se que, em sua formação, tenham estudado psicogênese da escrita, letramento, concepções pedagógicas, métodos de alfabetização, história da educação no Brasil, etc. Não estariam os professores preparados para alfabetizar? Por que os professores terminam os cursos de formação sem saber alfabetizar?

${ }^{2}$ Alfabetização baseada na ciência. Disponível em< ABC - AVAMEC>Acesso em 13/or/2021. 
Para a execução do PNAIC, divulga-se que foram investidos 2,7 bilhões de reais ${ }^{3}$, sendo I,I bilhão em 2013 e I,6 bilhão em 2014. ${ }^{4}$ Com todo esse investimento em formação e materiais didáticos os professores mudaram a prática pedagógica? $\mathrm{O}$ curso acrescentou qualidade ao ensino? $\mathrm{O}$ que podemos esperar com o PNA?

Estas políticas de alfabetização têm alto custo de investimentos. Há de se considerar, ainda que o Brasil não investe pouco em educação. "Atualmente, o país gasta no segmento cerca de 6\% do PIB (Produto Interno Bruto) por ano. O percentual é superior à média dos 36 países que compõem a OCDE (Organização para a Cooperação e Desenvolvimento Econômico), de 5,5\%”. (RIBEIRO, 2020).

Os resultados das avaliações externas têm mostrado que ainda há muito a se fazer para alcançar os objetivos de melhora na educação do país. Em 2007 o Ideb (índice de desenvolvimento da educação básica) observado na esfera pública do ensino fundamental foi de 4.o, em 2019, 5.7. (INEP, 2020).

Os professores de alfabetização do Brasil estão preparados para alfabetizar? Depende só do professor? Quais são os fatores que interferem na aprendizagem? Para argumentação teórica, foram utilizadas as bibliografias das autoras Ângela Kleiman (1995) e Magda Soares (1990, 1991), estudiosas do letramento, e Emília Ferreiro e Ana Teberosky (1984), pesquisadoras da psicogênese da escrita. Assim como Jean Piaget (1983), pesquisador e autor da epistemologia genética, onde estão os principais conceitos de aprendizagem deste texto.

\subsection{Breve contextualização dos métodos de alfabetização no Brasil}

Vários métodos de alfabetização foram defendidos até que se chegasse aos últimos debates e reflexões sobre a alfabetização no Brasil. Com o histórico fracasso nas avaliações da fase de alfabetização, estudos e reflexões atrelaram o insucesso da aquisição do código escrito aos métodos de ensino. Isto aconteceu quando o foco dos estudos da aprendizagem mudou de como o professor ensina para como o aluno aprende.

Métodos de alfabetização foram introduzidos nas escolas, a fim de que a criança aprendesse a ler e escrever com mais eficácia e que diminuíssem a repetência e a evasão escolar, como consequência da não aprendizagem.

Alguns métodos buscavam alfabetizar a partir de fonemas e de sílabas, sem significado para a aprendizagem e inserção do aluno no mundo da escrita, ou seja, pode-se afirmar que são métodos não

${ }^{3}$ Disponível em:< http://portal.mec.gov.br/ultimas-noticias/215-568057805/18221-pacto-preve-oferta-de-cursos-deformacao-para-36o-mil-professores $>$ Acesso em 12/o1/2021 
contextualizados. São, em geral, métodos que não levam em consideração as aprendizagens anteriores, que não entendem a aprendizagem através da ação do sujeito sobre o objeto, mas por repetição. A partir dos anos 1980, com os estudos sobre a psicogênese da escrita, inovam-se as concepções a respeito da alfabetização.

Os métodos de alfabetização são sintéticos ou analíticos. Nos métodos sintéticos, defende-se que se aprende do restrito para o amplo. De acordo com os métodos analíticos, a ideia defendida é que se aprende primeiro de uma forma global, partindo do todo para o restrito.

\subsection{Métodos sintéticos}

Os métodos sintéticos abrangem o alfabético, o fônico e o silábico. $\mathrm{O}$ método alfabético foi o método mais utilizado no Brasil, por meio das cartilhas de alfabetização. $\mathrm{O}$ método propõe que o professor ensine a partir das unidades menores (fonemas) até chegar ao texto. Primeiro ensina-se o nome de cada letra, depois é proposta a memorização das famílias silábicas, juntam-se as sílabas para formar palavras, seguidas de frases e de textos.

Este método é criticado pelos defensores da prática de ensino de alfabetização através do letramento, pois desvincula o sentido da leitura e escrita. Dessa forma, acreditam que, até aprender a ler, a criança já cansou da escola, já que repete muitos exercícios, até que tenha contato com um texto.

No método fônico ou fonético, trabalha-se com os sons das letras. Ensina-se que uma letra pode

representar diferentes sons, por exemplo: A letra O pode ter também o som Ó. E um som pode ser representado por diferentes letras, por exemplo: $\mathrm{C}=\mathrm{SS} ; \mathrm{CH}=\mathrm{X}$. A vantagem deste método é que a representação da escrita está relacionada ao som, já que é importante que se entenda a relação entre letra e fonema no processo de alfabetização. O que inclusive, é a proposta do ABC (Aprendizagem baseada na ciência), vinculada ao PNA. Porém, a crítica ao método é que se ensinam os fonemas a partir de cartilha que segue uma ordem no ensino das letras e fonemas. Primeiro são ensinadas as vogais, depois as consoantes. Primeiro ensina-se a decodificar as sílabas e palavras, para depois ser proposta a leitura de textos específicos.

No método silábico, ensina-se a partir de sílabas. Ao contrário do método fônico que defende que cada som é representado por uma letra, defende-se que pronunciamos sílabas quando falamos. Daí a memorização das famílias silábicas e textos específicos para cada conjunto de sílabas. Por exemplo: "O boi baba na Bia"; "Ivo viu a uva". A principal crítica a este método é que, apesar de não se demorar muito para a criança ter acesso à leitura de frases e de pequenos textos, estes costumam não ter sentido. Os textos costumam ser pobres em vocabulário, descontextualizados e não permitem a diversão que se deve 
ter, em especial por parte das crianças, ao realizar uma leitura. Além disso, quando os estudantes começam a escrever seus próprios textos, eles seguem o padrão de empobrecimento: sem conjunções que ligam uma frase à outra, pobres em vocabulário e criatividade. São textos com frases soltas e sem criatividade.

\section{I.4 Métodos analíticos}

Os métodos analíticos englobam palavração, sentenciação ou global. Indo de encontro aos métodos sintéticos, os métodos analíticos propõem o ensino do todo para o restrito. Neste grupo de métodos, defende-se a ideia de que a criança precisa ver sentido na leitura e na escrita.

No método palavração, primeiramente são ensinadas algumas palavras que fazem sentido às crianças, para depois dividi-las em unidades menores como sílabas e letras. $\mathrm{Na}$ sentenciação, ensinam-se sentenças de frases para depois passar às palavras, às sílabas e às letras. No método global, o ensino parte de um texto. O seu aspecto positivo é que mantém o interesse do aluno, já que a contação de histórias e leituras fazem sentido. Depois da memorização do texto, ele é dividido em sentenças até se chegar às sílabas. A crítica que se tem sobre este método é que não se aprende a ler, pois não se reflete sobre a estrutura da convenção da escrita. O texto é memorizado, mas não se reflete sobre a formação das palavras, ou seja, sobre a necessidade da utilização de determinadas letras e fonemas.

\subsection{Ciclos de alfabetização}

Nenhum dos métodos de alfabetização apresentados acima resultou em bons resultados da aprendizagem da leitura e da escrita das turmas de alfabetização. A história da alfabetização na educação pública brasileira resultou e continua, infelizmente, resultando em fracassos. Apesar do último Ideb, ter apresentado tímida melhora, o Brasil continua sendo um dos piores no PISA (Programa internacional de avaliação dos estudantes). Em leitura o Brasil ficou no ranking: $55^{\circ}$ e $59^{\circ}$ (INEP, 2019), dos 79 países participantes.

As reprovações no país são outro fator que buscou-se diminuir nas últimas décadas, visto que o Brasil é um dos países que mais reprova no mundo. Em 1996 a taxa de reprovação ao final da ${ }^{\underline{a}}$ série do ensino fundamental era de $41 \%$. (WEISZ, p. 224). A partir de 20II, aprova-se o aluno até o terceiro ano do ensino fundamental, independente de saber ler, interpretar e escrever, pois tornou-se um ciclo de alfabetização. O Parecer CNE/CEB № II/zoro orienta que os três primeiros anos do Ensino Fundamental sejam organizados em um único ciclo de aprendizagem, inclusive em escolas que são seriadas, para que não haja retenção dos alunos. Diz o Parecer CNE/CEB № ıI/2oı: 
A proposta de organização dos três primeiros anos do Ensino Fundamental em um único ciclo exige mudanças no currículo para melhor trabalhar com a diversidade dos alunos e permitir que eles progridam na aprendizagem [...]. Para garantir a aprendizagem, as escolas deverão construir estratégias pedagógicas para recuperar os alunos que apresentarem dificuldades no seu processo de construção do conhecimento. (grifo meus)[...] Para evitar que as crianças de 6 (seis) anos se tornem reféns prematuros da cultura da repetência e que não seja indevidamente interrompida a continuidade dos processos educativos levando à baixa autoestima do aluno e, sobretudo, para assegurar todas as crianças uma educação de qualidade, recomenda-se enfaticamente que os sistemas de ensino adotem nas suas redes de escolas a organização em ciclo dos três primeiros anos do Ensino Fundamental, abrangendo crianças de 6 (seis), 7 (sete) e 8 (oito) anos de idade e instituindo um bloco destinado à alfabetização.

O ciclo sustenta-se na ideia de que nos três primeiros anos do ensino fundamental, sendo um ciclo de alfabetização, a criança tem de avançar, sem ficar retida, para dar continuidade ao processo. Caso o primeiro e o segundo ano não deem conta da alfabetização, os alunos têm, ainda, o terceiro ano para consolidar a alfabetização. Sabemos que a reprovação não colabora para a aprendizagem, ao contrário, colabora para a evasão escolar. Porém, permitir que o aluno progrida de um ano ao outro, sem "recuperar os alunos que apresentarem dificuldades no seu processo de construção do conhecimento", também não faz sentido. Permitir que o aluno fique cada ano mais defasado em relação ao ano anterior não é a solução que se espera para a melhoria da educação, a não ser que o único interesse seja a redução de gasto público, já que cada aluno matriculado tem um custo ao governo.

Até 20II, nas escolas que não são organizadas por ciclo, a criança iniciava o primeiro ano do

ensino fundamental e, caso não aprendesse a ler, interpretar e escrever, ficava retida na série, sem avançar para a segunda série no próximo ano escolar. Isso representava um fracasso nos índices de aprovação do Brasil, pois em torno de 40\% reprovavam logo no primeiro ano de entrada na vida escolar, como já mostrado anteriormente. Todavia, muitas crianças continuam terminando o primeiro ciclo do ensino fundamental sem os objetivos de aprendizagens alcançados. A reflexão que se faz é onde está ou estão os problemas com a educação do Brasil? Falta investimento público? Os professores têm boa formação profissional? Se saem das licenciaturas com lacunas na formação, o que se tem feito para acompanhar e melhorar o ensino universitário? Por que crianças com três anos consecutivos voltados à alfabetização continuam não aprendendo a ler e a escrever?

\subsection{Ler e escrever: uma construção}

Foi Jean Piaget (1983) o criador da epistemologia genética, que deu origem ao pensamento construtivista da aprendizagem. Ele foi orientador do doutorado de Emília Ferreiro na Universidade de Genebra. A partir dos anos 8o, o pensamento construtivista chegou à alfabetização, com os estudos de 
Emília Ferreiro e Ana Teberosky (1984), que pesquisaram a construção do sistema de escrita por parte da criança.

Jean Piaget estudou o desenvolvimento humano a partir do nascimento e seus estudos mostram como a aprendizagem depende do desenvolvimento o qual é explicado por meio de quatro fatores: maturação, experiência física e lógico-matemática, transmissão social e equilibração (BECKER, 20I2). Atualmente, sabe-se que a vida intrauterina traz reflexos no desenvolvimento e aprendizagem.

Piaget não explorou a construção da escrita e da leitura pela criança, mas foi a partir de sua teoria que Emília Ferreiro desenvolveu seus estudos, resultando na Psicogênese da escrita. Uma fundamental colaboração de Piaget e Ferreira é que a criança aprende por meio da ação e não da pura transmissão. Isto fez com que as concepções na educação mudassem o foco. Se antes o foco era de como se ensina, a partir dos anos 80 passa a ser o de como se aprende.

Os estudos de Ferreiro e Teberoski passaram a fazer parte obrigatória nos cursos de formação de professores, simpósios e congressos. Inclusive, são as suas ideias que embasam os Parâmetros Curriculares Nacionais (PCNs) e o material de formação do PNAIC.

No início dos anos 8o, começaram a circular, entre educadores, livros e artigos que davam conta de uma mudança na forma de compreender o processo de alfabetização; deslocavam a ênfase habitualmente posta em como se ensina" e buscavam descrever como se aprende - . Tiveram grande impacto os trabalhos que relatavam resultados de investigações, em especial a psicogênese da língua escrita (BRASIL, 1997, p.20)

Estes estudos e suas decorrentes práticas chegaram às universidades brasileiras e aos cursos de formação, entrando com força na prática pedagógica de professores que entenderam que, para aprender, é necessário que haja sentido no que se está aprendendo. É lendo que se aprende a ler, e escrevendo, e não apenas copiando, que se aprende a escrever, e isso ocorre por meio da ação, que é beneficiada pelas experiências que o meio social e físico proporciona. Por isto a importância de um ambiente alfabetizador, de um professor desafiador e a liberdade de escrever mesmo sem ter o domínio do código escrito.

Por volta dos anos 80 e 90 , os estudos relativos à aquisição do código escrito foram se intensificando e chegou-se ao conceito de letramento, discutido no Brasil por Magda Soares, Ângela Kleiman e Arthur Gomes de Moraes, os quais relacionam a alfabetização com o letramento, ou seja, entendem que um processo não pode ser independente do outro. Mas, apesar de o letramento ser essencial à alfabetização, estes dois conceitos não se confundem. A alfabetização é a aquisição do código escrito (SOARES, 2003) enquanto o letramento está relacionado ao uso social que se faz da escrita.

Alfabetizar está mais relacionado ao ato de ensinar a decodificação da leitura e a codificação gráfica. No entanto, é possível ser alfabetizado (saber ler) e não ser letrado. É o caso de pessoas que leem 
um texto, mas não o compreendem. Na escola, presenciamos crianças que ao terminarem de ler um texto, poesia, ou frase, não sabem o que leram. O inverso também acontece. É possível ser letrado sem ser alfabetizado. Pode-se saber pegar um ônibus, entender placas de trânsito, sem saber ler e escrever. Pessoas que entendem uma mensagem lida por outra pessoa, que se interessam em ouvir leitura por outros e compreendem um jornal, apresentam nível significativo de letramento, porque fazem uso social da escrita (SOARES, 1990).

No Rio Grande do Sul, a Psicogênese da escrita se fortaleceu tanto que, em 1970, funda-se o GEEMPA (Grupo de estudos sobre educação, metodologia e ação), comandados por Esther Grossi.

Emília Ferreiro trouxe resultados da sua pesquisa de como ocorre o processo de aquisição da escrita, mostrando níveis que o sujeito perpassa até chegar à escrita ortográfica. Ferreiro não sugeriu atividades pedagógicas adequadas para cada nível, mas demostrou os processos que a criança percorre, criando hipóteses na construção da linguagem escrita. O objetivo de Emília Ferreiro foi o de entender como a criança aprende a ler e a escrever, não o de criar estratégias para ensinar.

Emília Ferreiro provou que todas as crianças constroem hipóteses em relação à escrita, resultando em níveis que vão avançando desde uma escrita representada somente por desenhos, passando pelo nível em que a criança usa qualquer letra para escrever alguma palavra, depois avança para o nível em que usa uma letra para cada sílaba pronunciada, até chegar no nível ortográfico. Emília Ferreiro não criou atividades específicas para serem usadas em cada nível da escrita. Com base nestes estudos, Esther Grossi elaborou com o grupo de estudos do GEEMPA, atividades de alfabetização adequadas a cada nível que ela denominou de: Pré-silábico, Silábico (podendo ser com ou sem valor sonoro), Silábico alfabético, alfabético e ortográfico, para auxiliar que o aluno avance nas suas hipóteses da linguagem escrita. Em Porto Alegre, este material didático foi adotado em muitas escolas como base para a alfabetização.

Tanto Jean Piaget quanto Emília Ferreiro não desenvolveram métodos de ensino, mas demostraram, através de suas pesquisas, como se aprende: a aprendizagem depende de um processo de construção, daí o nome construtivismo.

O construtivismo é uma forma de explicar os processos de desenvolvimento cognitivo e aprendizagem humana, portanto, tratar o construtivismo como método é um equívoco. Outro equívoco da interpretação do construtivismo é entender que a criança se desenvolve apenas pela maturação, pois o desenvolvimento cognitivo, como dito acima, depende de quatro fatores: maturação, experiência física e lógico-matemática, transmissão social e equilibração.

Pela má interpretação desta fundamentação, existiram alguns que, por se julgarem construtivistas, não ensinavam os alunos (SANTO, 2015, p.I). Proporcionavam um ambiente letrado, 
cheio de jogos, livros de literatura infantil, na crença de que a criança iria aprender sozinha. Este modelo está relacionado com a concepção aprioristas da aprendizagem. Esta atitude profissional resultou em algumas críticas ao construtivismo pelo fracasso na alfabetização. "A escola está do jeito que está porque o construtivismo não deu certo”. Frase comum de ser ouvida entre os professores da escola. E o que se constata, ainda, são práticas de alfabetização que não alcançam a todos. Ou se proporciona um ambiente letrado, alfabetizador, mas não se faz a intervenção necessária ao estudo do sistema da escrita, perceber os fonemas, relacionar uma escrita à outra, ou se tem métodos tradicionais, tecnicistas, como começar o ensino pelas letras, sendo primeiro as vogais, em seguida as consoantes. Depois leitura e memorização de palavras formadas por cv-cv (consoante vogal, consoante-vogal), como por exemplo: bebê, babá, boi, oi, ui, ai, ei, bola, bolo etc, para só no final do ano letivo ler e escrever um texto.

Emília Ferreiro e Ana Teberosky constataram, por meio de seus estudos, que esses métodos de alfabetização não auxiliam que as crianças façam relações com o que já sabem, não favorecendo o processo de assimilação. Elas salientaram que é necessário ler para aprender a ler. Não se pode esperar que primeiro o aluno saiba decodificar um texto para então apresentá-lo em aula. É escrevendo que se aprende a escrever, ressaltando que "escrever não é o mesmo que copiar" (Ferreiro e Teberosky, 1984). Daí a importância de desafiar o aluno a escrever, de acordo com o seu pensamento, o que não quer dizer que não se tenha que intervir pedagogicamente para que aprenda. Antes de se ter o conhecimento necessário para a produção de um texto, a professora pode servir de escriba em um texto coletivo com os alunos. Isto favorece a prática da oralidade, necessária à elaboração de ideias. Mas depois da escrita, é importante reler com os alunos, encorajá-los a ler também, mesmo que num primeiro momento só por memorização, mostrando cada palavra de uma frase enquanto se lê em voz alta.

O que Emília Ferreiro mostrou em Reflexões sobre alfabetização, nos anos 8o, continua atual: as crianças veem muitas escritas fora da escola (placas de lojas, rótulos de embalagens, letreiros de ônibus, nomes de ruas) mas na escola "a informação é frequentemente descontextualizada" (200I, p. 39).

$\mathrm{Na}$ prática metodológica das professoras alfabetizadoras da escola observada, pela cultura do caderno cheio e pela resistência em trabalhar com a escrita espontânea (e não que o professor deva deixar o aluno avançar sozinho em suas hipóteses, pelo contrário, deve refletir a língua escrita, mostrar porque as palavras são formadas por tais e tais letras) que ainda há a cultura do caderno cheio. Práticas de ensino onde se enche o quadro para as crianças copiarem, já que ver o caderno cheio alegra os pais que defendem que "esta professora é boa". Porém, estas práticas podem "matar" a alegria de aprender. É comum a criança chegar com muita empolgação na escola, com muita vontade de ler e escrever e não demorar muito para começar a achar a escola chata, visto que se demora muito tempo para escrever (diferente de 
copiar) e ler. São meses memorizando letras, sílabas, treinando coordenação motora fina, para só depois escrever e ler de fato, ainda que a leitura seja por parte da professora num primeiro momento.

Compreender a escrita como um código social é fundamental para Emília Ferreiro e Ana Teberosky. Também para professores que não esperam a criança saber ler para ler e saber escrever para escreverem. Ferreiro ressalta que o professor deve trabalhar com diversos textos desde o início da alfabetização: leitura de imagens, receitas, poesias, notícias, parlendas, músicas folclóricas, contos de fada, histórias em quadrinhos, etc. A proposta do PNAIC foi com base neste tipo de alfabetização.

Neste percurso de discussões e reflexões teóricas, algumas confusões, incertezas e arraigamento à educação tradicional ainda perpassam as práticas pedagógicas de professores alfabetizadores. Alguns professores confundem os conceitos como letramento e construtivismo ao afirmarem que não concordam com estes "métodos" porque não dão certo. Percebe-se a confusão ao entenderem construtivismo e letramento como métodos. O que se pretende é que se alfabetize utilizando-se as escritas sociais presentes em nossa sociedade. De acordo com Morais (2005), alfabetizar letrando. Ressalta-se ainda, que estudos científicos, apontados no curso $\mathrm{ABC}$, mostram que associar a escrita ao som da fala, ou seja, consciência fonêmica, é fundamental para uma boa alfabetização.

\subsection{Práticas de alfabetização após o PNAIC e concepções de aprendizagem}

As práticas de alfabetização aqui referidas são fruto de observações em aulas e reuniões pedagógicas numa escola municipal de Porto Alegre, bem como conversa informal entre professores e acesso aos planejamentos e atividades didáticas, especialmente as chamadas "folhinhas".

A bagagem cultural que a criança traz quando chega à escola é de suma importância no processo de alfabetização. Por isto, crianças que participam de eventos de letramento (KLEIMAN, 2007) desde o nascimento alfabetizam-se mais facilmente do que crianças cujas famílias não têm a cultura da leitura. "O fato de poder comportar-se como leitor antes de sê-lo, faz com que se aprenda precocemente o essencial das práticas sociais ligadas à escrita" (FERREIRO, 200I, p. 6o). Todavia, o não se alfabetizar no primeiro e segundo ano do ensino fundamental, não pode ser transmitido à história de vida da criança antes da escolarização. "Ela ainda não está pronta”, “é fraquinha”, são ideias inaceitáveis, porque acredita-se que a criança é capaz, desde que colocada em um ambiente onde se possa construir este saber e o professor tenha consciência do processo de aprendizagem e o que é ou não adequado a cada nível de aprendizagem e o que vai favorecer a evolução desta.

Apesar de a bagagem cultural do aluno contar e muito na alfabetização, há de se insistir na função pedagógica do professor. Se crianças que chegam à escola com um histórico de famílias que têm o hábito 
de leitura, que fornecem livros de literatura, mesmo antes de elas saberem decodificar a palavra, aprendem mais facilmente a ler e escrever, e isto é fato, então por que alguns professores continuam a extensão de casa do aluno ao não favorecer um ambiente alfabetizador e ter práticas de leituras com os alunos? Porque continuam iniciando as aulas com sílabas soltas no quadro como atividades para copiarem e resolverem. Muitas atividades copiadas do quadro: completar com sílabas, preencher a letra que falta, contar o número de letras. Não que este estudo da língua seja dispensável, pelo contrário, Artur Gomes de Morais (2005) faz a análise de que é preciso esta reflexão analítica da língua, mas não desmembrada do processo de letramento, tampouco mecânico.

Por que não iniciar a aula com a contação de uma história? Com uma parlenda? E a partir daí, refletir sobre letras e fonemas, bem como sílabas de cada palavra, quantas palavras em cada frase, ler as frases, textos, pensar e escrever, etc. Na escola observada, em uma reunião de professoras alfabetizadores, uma das professoras disse: "Eu não, que chatice contar historinha". Se a queixa maior entre as professoras é de que os alunos têm dificuldade para se alfabetizarem porque vêm de um ambiente desfavorecido economicamente e com outra cultura, que não o da prática de leitura, então a escola poderia/deveria tentar suprir esta defasagem e instigar nelas o gosto pela leitura e vontade de querer ler. Porém, o professor só vai conseguir formar leitores, se ele for um.

O material de formação do PNAIC discute concepções de aprendizagem, traz argumentos teóricos de referências intelectuais no assunto, bem como exemplos de sequência didática para serem trabalhadas em aula e jogos de alfabetização. Foi enviado diversos livros de literatura infanto-juvenil para ficarem disponíveis aos alunos e os professores trabalharem em sala de aula.

Observou-se como algumas professoras que participaram do PNAIC estão alfabetizando. No geral, continuam com uma metodologia descontextualizada, de alfabetização centrada na repetição e memorização de sílabas, descontextualizado do seu uso social. As atividades continuam sendo palavras para completar com sílabas, continhas ensinadas a partir do quadro e giz, sem utilização do material concreto e folhinhas copiadas de livros didáticos. Esta metodologia de ensino está relacionada à concepção que o professor tem da aprendizagem. Pouco adianta o governo investir em curso de capacitação à alfabetização se uma mudança de concepção não for intrínseca ao profissional da educação.

Enquanto for oferecido cursos de formação continuada, e isto é necessário, mas sem a reflexão de como a aprendizagem acontece, pouca efetividade se terá nas mudanças das práticas pedagógicas porque

O sujeito pode transformar indefinidamente sua capacidade cognitiva e de aprendizagem, porém só poderá exercê-la dentro dos limites de sua concepção epistemológica; um professor não poderá exercer uma pedagogia e uma didática inspiradas no construtivismo se continuar preso a concepções epistemológicas 
empiristas ou aprioristas. É por isso que professores, ao assumirem uma nova moda didático-pedagógica, na medida em que se esforçam para dar conta dessa novidade vão retrocedendo até retornarem às formas costumeiras que desejavam superar (BECKER, 2008, p.55)

Por isto há de se questionar: as faculdades, principalmente de pedagogia, que forma os profissionais da alfabetização, estão proporcionando aporte teórico, debates e reflexões a respeito das diversas concepções de aprendizagem? Não adianta ensinar como fazer se não for trabalhado a consciência do porquê fazer. Se não, acontece o que foi observado nesta escola: as professoras passam por uma formação extensa, com custos para o governo, e pouco muda-se a prática, porque a consciência da construção da aprendizagem não foi assimilada. Então, na maioria das vezes, repete-se o modelo de como fomos ensinados: Quadro cheio, decorar as letras, as famílias silábicas, ler frases sem sentido e curtas como "O boi baba ou Eva viu a uva", treinar a grafia no caderno de caligrafia para só depois começar a produzir suas próprias frases e ler textos mais interessantes e conectados à função social da escrita.

Nenhuma prática docente é neutra. Em geral, nas escolas públicas brasileiras os professores têm autonomia para planejarem e aplicarem seu planejamento, sem observação, sugestão ou até trocas reflexivas entre os colegas. Não se discute o ensino e a aprendizagem. Com isto, não se percebe que cada prática traz consigo a convicção do professor a respeito de como se aprende. Esta concepção é inconsciente, revela-se através das falas e metodologias de ensino.

A prática pedagógica centrada na repetição está relacionada com a concepção empirista da aprendizagem. Professores empiristas não levam em consideração a ação do aluno na construção do conhecimento. Acreditam que a aprendizagem se dá por repetição, que é repetindo atividades como decorar sílabas que o aluno vai aprender. O conhecimento, neste caso, é dado pelo professor, pois é externo ao sujeito. O professor é transferidor de conhecimento ao aluno, como se este fosse uma folha em branca a ser preenchida.

Outra observação significativa foi com relação à caixa de jogos enviadas pelo MEC para cada sala de aula do primeiro ciclo, e aos livros de literatura infanto juvenil. Das doze turmas de alfabetização, em duas delas as professoras disponibilizaram os livros na sala de aula para os alunos lerem e folhearem. Uma professora utiliza os jogos de alfabetização. As demais mantêm os materiais fechados dentro do armário do professor. As caixas de jogos permanecem fechadas, sem nunca terem sido usadas. Questionada sobre o porquê destes materiais estarem fechados dentro de um armário, porque de os livros não estarem ao alcance das crianças, uma professora respondeu que é para que as crianças não estraguem o material: "Se eu deixar eles pegarem, vão rasgar tudo". Quanto aos jogos: "É difícil e não dá pra fazer com a turma toda”. 
Outra prática da alfabetização equivocada, mas de acordo com a concepção apriorista, ainda que inconscientemente, é de uma professora "despertar" o interesse no aluno para que este aprenda, mas sem a intervenção necessária. Jean Piaget chama de transmissão social. Ora, se a criança não for ensinada que as letras têm nome, e cada uma delas representa um ou mais sons da língua, se não for ensinada a perceber estes sons na escrita e leitura, sozinha não irá conhecer. Transmissão social é o mesmo que outros teóricos como Vygotki chamam de mediação. Colocar jogos, caixas com leituras, equipar a sala de aula com números e alfabetos e não ensinar a criança, pensando que tendo isto à disposição ela irá despertar e aprender sozinha, é uma concepção apriorista da aprendizagem. Como se as estruturas fossem inatas ao sujeito.

Mas há professores que procuram contextualizar a língua portuguesa e a matemática nas atividades propostas aos alunos. Dentre as professoras que fazem uso de material dourado para ensinar matemática, usam músicas e parlendas para alfabetizar, recitam poesias com os alunos e jogam bingo bingo de números, bingo do alfabeto, bingo de palavras, bingo silábico e bingo de rimas - aconteceu um fato interessante. Uma aluna do terceiro ano do ensino fundamental parou na porta da sala de uma professora que foi sua em outro ano e disse: "como eu queria ser desta turma"! A turma estava, naquele momento, ouvindo uma música folclórica enquanto acompanhavam com a letra impressa da canção.

A prática pedagógica desta professora está em consonância com as propostas do PNAIC, que tem embasamento na psicogênese da escrita e a concepção interacionista da aprendizagem. Nesta concepção, o professor não é o transferidor do conhecimento, mas cria situações nas quais o aluno sinta-se desafiado a aprender. Sabe, também, que os desafios precisam estar de acordo com a capacidade cognitiva desenvolvida por cada criança até aquele momento. A professora alfabetizadora que utiliza as contribuições da epistemologia genética e da psicogênese da escrita sabe que a criança só aprenderá se ver sentido no que está aprendendo, se o ensino estiver relacionado com a escrita que ela encontra fora da escola. Observou-se ainda, que essa professora, ao fazer o jogo do bingo de letras com os alunos, ao invés de dizer o nome da letra sorteada, fazia o som da letra, levando os alunos a relacionarem a escrita aos fonemas.

Aprender é complexo. Para Piaget, para que a aprendizagem aconteça, são necessários os quatro fatores a seguir:

O primeiro de todos, a maturação (...) uma vez que esse desenvolvimento é uma continuação da embriogênese; o segundo, o papel da experiência, dos efeitos do ambiente físico na estrutura da inteligência, o terceiro, a transmissão social em sentido amplo (transmissão por linguagem, educação, etc); e o quarto fator, que é com frequência negligenciado, mas que me parece fundamental e até o fator principal. Chamarei a este 
fator de equilibração, ou se preferirem, de autoregulação (PIAGET, 1995, p. 2, apud, BORGES e FAGUNDES, 2016, p.3)

A maturação é a aprendizagem em si. Refere-se ao desenvolvimento das estruturas cognitivas, à capacidade que vai permitir com que o sujeito adquirira novos conhecimentos relacionados aos conteúdos. Ou seja, para a aprendizagem acontecer são necessárias condições estruturais já construídas para isto. A experiência física é a ação do sujeito sobre o objeto. Objeto entendido como tudo o que não é o sujeito: as outras pessoas, jogos, os animais os objetos, etc. A transmissão social é o ensino do conhecimento historicamente acumulado, dos quais sozinho ninguém aprende, como já mencionado anteriormente. A equilibração é quando há um equilíbrio entre a assimilação, que é a incorporação de elementos novos a uma estrutura que já existe e a acomodação, que consiste em acomodar este novo conhecimento, ocorrendo uma mudança na estrutura. (MARQUES, 2008).

\section{I.7 A colaboração da neurociência na educação}

Os estudos da neurociência têm sido apontados cada vez mais nos cursos de formação de professores. Não poderia deixar de sê-lo visto, a necessidade de se entender o funcionamento cerebral, principalmente no que se refere ao cognitivo e todos os componentes que formam o sujeito: ambiente, biológico, psicológico, pedagógico e até mesmo o espiritual, levando-se em conta a formação moral de cada família, entre outros.

As investigações mostram que o desenvolvimento tem a ver com a genética e com o meio social do ser humano. O que não contradiz os estudos de Piaget. Estes estudos mostram o quão importante é as interações e as intervenções para que a criança se desenvolva e aprenda.

Quase desde o começo, o estudo do desenvolvimento humano tem sido interdisciplinar. Alimenta-se de um amplo espectro de disciplinas que incluem psicologia, psiquiatria, sociologia, antropologia, biologia, genética, ciência da família (estudo interdisciplinar sobre as relações familiares), educação, história e medicina. (PAPALIA, FELDMAN, p.37, 2013)

O processo de aprendizagem do ser humano é complexo. O professor não precisa ser um especialista em neurociência para dar aula, mas é fundamental compreender o processo que ocorre na complexidade cerebral para a aprendizagem. Aprender envolve diversos fatores como já foi citado em Piaget. Os estudos em neurociência são importantes porque mostram que o ambiente pode modificar a genética. Por exemplo, uma criança que tem a pré-disposição de ser alta, se for subnutrida não irá crescer, porque o meio modifica a genética, isto é chamado de epigenética. Portanto, um ambiente onde há a 
negligência nos cuidados, ou ausência de meios que proporcionem a experiência física, causarão inúmeros impactos no desenvolvimento cerebral.

Assim como entender que somos constituídos a partir das interações sociais e culturais, além da biológica, também compreende-se porque alguns alunos são tímidos, falantes, inseguros, autoconfiantes, criativos, passivo em relação aos outros e as situações sociais. Isto tem relação com a base familiar e o ambiente em que se vive, desde a vida intrauterina.

Se entende-se que "a motivação e a autoconfiança são fatores importantes para o sucesso na escola, enquanto emoções negativas como a ansiedade podem prejudicar o desempenho" (PAPALIA, FELDMAN, p.38, 2013), ao se deparar com estas situações em sala de aula, tem-se uma postura pedagógica afetiva que colabore para o desenvolvimento e envolvimento do aluno, fazendo com que este sinta-se confortável onde está. Se o professor não compreende estes aspectos psicológicos, pode ter uma postura que cause ainda mais ansiedade, prejudicando a aprendizagem do aluno.

É comum os professores presenciarem, criança nas turmas de alfabetização que a qualquer atividade proposta diz: "não consigo", "é muito difícil", "não sei desenhar", etc. Não sei e não consigo são frases muito ouvidas no início do ano letivo, quando não acompanhadas de lágrimas. Logo reflete-se sobre que vivências familiares e sociais tais crianças vivenciam? Não raras vezes a postura da professora faz toda a diferença, como um elogio naquilo que a criança começa a apresentar em aula, o que vai fazendo com que se tornem mais confiantes.

É importante compreender que o desenvolvimento não se dá somente no âmbito do biológico, mas observar como as crianças assimilam e entendem o mundo através de suas experiências com este. É na interação com o meio que o desenvolvimento ocorre. (RODRIGUES, 2020). Não vem pronto, como se o sujeito recebesse tudo de fora, tampouco depende só deste, como se bastasse os aspectos biológicos estarem maduros, e o sujeito consegue aprender sozinho. Como acredita-se que acontece no empirismo e inatismo ou apriorismo.

Se compreende-se que a aprendizagem se dá pelo interesse e pelas estruturas cerebrais (préconhecimento a respeito do que se vai trabalhar), propicia-se os desafios de acordo com a capacidade de cada um. Para Piaget (1972) o desenvolvimento passa por etapas fixas, mas que são variáveis em cada sujeito conforme o meio em que ela vive. Colabora para esta afirmação, Becker e Marques (200I, p.6I)

[...] não adianta continuar insistindo em perguntar o que a criança ou adolescente já sabe, porque isto não desafia, antes aborrece, além de dar a sensação de que não está sendo desafiado porque é incapaz. Tampouco adianta perguntar o que está muito além de sua capacidade. Se isso acontece com frequência, ao invés de ser sentido como desafio, pode produzir uma frustração exagerada, a qual acarreta sentimento de incapacidade. 
Portanto, entender que aprendemos de acordo com as estruturas cerebrais é de suma importância para que se obtenha bom desempenho na prática pedagógica e evolução dos alunos envolvidos neste processo.

A pesquisa em neuroplasticidade, inter-relacionada ao desenvolvimento humano, contribui e muito, para a área de educação. Compreender que as sinapses neuronais podem se modificar e se reestabelecer através das experiências, leva enquanto educadores, não se conformar quando determinado aluno apresenta defasagem em termos de conhecimento em relação aos demais colegas, assim como não julgar logo no início do ano letivo quem vai ou não conseguir aprender.

Estes estudos orientam que as intervenções e os desafios são imprescindíveis para que novas conexões cerebrais ocorram.

A análise desses estudos faz refletir sobre o papel da escola, professores, família, entre outros, no processo de ensino e aprendizagem. No entanto, verifica-se que cada um possui uma função importante para o desenvolvimento da aprendizagem. Não pode-se delegar o fracasso da alfabetização apenas a alguns. Diferentes fatores contribuem para o bom funcionamento do cérebro e influenciam na plasticidade neural, e isso é da responsabilidade de todos. (LIMA, p.27, 2000)

O PNA coloca a importância da ciência cognitiva para a alfabetização: "fundamentação de programas e ações em evidências provenientes das ciências cognitivas adoção de referenciais de políticas públicas exitosas, nacionais e estrangeiras, baseadas em evidências científicas; (Art. $3^{\circ}$ ); considera a importância de um conjunto de pessoas e ações: "reconhecimento da família como um dos agentes do processo de alfabetização.”

No artigo 7, responsabiliza os agentes envolvidos:

Art. $7^{\circ}$ São agentes envolvidos na Política Nacional de Alfabetização:

I - professores da educação infantil;

II - professores alfabetizadores;

III - professores das diferentes modalidades especializadas de educação;

IV - demais professores da educação básica;

$\mathrm{V}$ - gestores escolares;

VI - dirigentes de redes públicas de ensino;

VII - instituições de ensino;

VIII - famílias; e

IX - organizações da sociedade civil.

Para o PNA, é com o trabalho colaborativo de famílias, professores, escolas, redes de ensino e poder público que será possível elevar a qualidade da alfabetização e combater o analfabetismo em todo o território brasileiro. Não depende só da família, ou só da escola. Tampouco do interesse do aluno. 
Aprender envolve uma complexidade cerebral que vai desde a maturação biológica, da vida intrauterina às experiências com o meio, a transmissão social e a equilibração, dada novas sinapses cerebrais.

\section{Considerações finais}

O fato de alguns professores não se abrirem para novas práticas de ensino leva a alguns questionamentos: Os professores querem ou/e sabem alfabetizar? Por que tantos alunos chegam ao terceiro ano do ensino fundamental sem saberem a letra inicial das palavras? Qual a concepção de aprendizagem que cada professor traz consigo? Qual concepção de aprendizagem prevalece na escola? Compreende-se os diversos fatores que envolvem o aprender?

As políticas públicas de formação de professores como o PNAIC e o atual ABC geram gasto de recurso público com o objetivo de qualificar os professores alfabetizadores para que todas as crianças sejam alfabetizadas seja até o segundo ou terceiro ano do ensino fundamental. A constatação, após a formação, é que ainda há um bom número de alunos que chegam ao terceiro ano do primeiro ciclo sem fazer relação letra som, dado mostrado nas últimas avaliações externas e o PISA. Este problema, certamente, deve ser vinculado a diversos fatores, sem responsabilizar, unicamente, professores, família ou nível econômico das crianças. Não foi discutido aqui as crianças público-alvo da educação especial. Contudo, há de se repensar se as formações trazem mudanças nas práticas de alfabetização e como a formação da graduação está formando seus professores. É essencial estudar como o ser humano aprende e os fatores envolvidos.

A observação dos resultados avaliativos e postura pedagógica de professas que participaram do PNAIC, mostra que não há mudanças significativas, pelo menos no contexto observado, o que leva a pensar que o investimento em formação, apesar de necessário, não é o suficiente para levar às mudanças esperadas.

O PNA considera a função da família enquanto primordial na alfabetização das crianças e traz uma formação baseada em estudos científicos que colocados em prática em Portugal mostraram bons resultados. Mas enquanto os professores não compreenderem e assimilarem que os métodos de alfabetização, seja por meio de decorar famílias silábicas, seja de proporcionar um ambiente letrado, seja por consciência fonológica, não são eficazes se não compreenderem o processo de aprendizagem, os governos continuarão a gastar com formações que não alcançam o objetivo de erradicar o analfabetismo no país.

Outro aspecto muito relevante é a não universalização da educação infantil, que deveria ter sido alcançada de acordo com PNE. 
Se no Brasil recebemos nas escolas públicas crianças que não frequentaram a educação infantil e a vivência familiar não colaborou de forma positiva para a aprendizagem das letras, do desenvolvimento da oralidade e capacidade de interpretação oral, a tendência é que se leve mais tempo para a criança se alfabetizar. Portanto, urge que as crianças brasileiras frequentem a educação pré escolar e os professores compreendam processos de aprendizagem.

\section{Referências bibliográficas}

ANNUNCIATO, Pedro. O bê-á-bá dos métodos de Alfabetização. Revista Nova Escola. [s/d]. Disponível em: 〈https://novaescola.org.br/conteudo/r7568/o-be-a-ba-dos-metodos-de-alfabetizacao\#> Acesso em I4 de jan. de 202I.

BASE Nacional Comum Curricular (BNCC). Disponível em: http://basenacionalcomum.mec.gov.br/images/BNCC_EI_EF_IIO5I8_versaofinal_site.pdf> Acesso em Io de jan. de 2021.

BECKER, Fernando. Aprendizagem - concepções contraditórias. Revista eletrônica de psicologia e epistemologia genética. Volume I no I - Jan/Jun, 2008 p. 53-73.

BECKER, Fernando. Educação e construção do conhecimento. $2^{\underline{a}}$ ed. revista e ampliada. Porto Alegre: Penso, 2012.

BECKER, Fernando; MARQUES, Tânia B.I. e. Aprendizagem humana: processo de construção. Pátio Revista pedagógica. Porto Alegre: Artmed. Ano 4, n.15, nov20oo/janzoor.

BORGES, Karen Selbach; FAGUNDES, Léa da Cruz. A teoria de Jean Piaget como princípio para o desenvolvimento das inovações. Educação Revista Quadrimestral. Porto Alegre, v. 39, n. 2, p. 242-248, maio-ago. 2016 ISSN 1981-2582. Disponível em: < file:///C:/Users/evand/Downloads/21804Texto\%20do\%20artigo-102691-3-10-20160913.pdf> Acesso em: 30 de nov. de 2020.

BRASIL. Secretaria de Educação. Parâmetros curriculares nacionais. Disponível em:< http://portal.mec.gov.br/seb/arquivos/pdf/livroo2.pdf >em I4 de jan. de 202I.

BRASIL. Lei no 12.796, de o4 de abril de 2013.Diretrizes e bases da educação nacional. Disponível em: <http://www.planalto.gov.br/ccivil_03/_ato20II-2014/2013/lei/li2796.htm> Acesso em Io de jan. de 2021.

BRASIL. Decreto no 9.765, de ir de abril de 2019. Institui a Política Nacional de Alfabetização. Disponível em:< https://www.in.gov.br/materia/-/asset_publisher/KujrwoTZC 2 Mb/content/id/71137476/dore2019-04-II-decreto-n-9-765-de-II-de-abril-de-2019-7113743I> Acesso em II de jan. de 202I.

FERREIRO, Emília e TEBEROSKY, Ana. A psicogênese da língua escrita. Porto Alegre: Artes Médicas, I984.

Reflexões sobre alfabetização. $24^{\circ}$ ed. São Paulo: Cortez, 200 I. 
IBGE. INDICADORES. Disponível em: <https://www.ibge.gov.br/indicadores.html> Acesso em ro de jan. de 202I.

INEP- Instituto Anisio Teixeira. Disponível em: < https://www.gov.br/inep/pt-br > Acesso em I4 de jan. de 202I.

INSTITUTO PAULO MONTENEGRO Ação Social do Ibope. Disponível em: 〈https://ipm.org.br/inaf> Acesso em o8 de jan de 2021.

KLEIMAN, Ângela. Texto Leitor. Aspectos cognitivos da leitura. Campinas SP: Pontes, 1989.

KLEIMAN, Ângela. Os significados do letramento. Campinas: Mercado de Letras,I995.

KLEIMAN, Ângela. Letramento e suas implicações para o ensino de Língua Materna. Signo. Santa Cruz do Sul, v. 32 n 53, p. I-25, dez, 2007

LIMA, Maria do Carmo Gonçalves da Silva. Plasticidade neural, neurociência e educação: as bases do aprendizado. Mudi, v. 24, n. 2, p. 30-41, ano 2020. (Material disponibilizado pelo curso AEE/UFPEL/2020.

MARQUES, Tânia Beatriz Iwaszko. Epistemologia Genética. IN: Psicologia e Educação. Perspectiva teórica e implicações. Salles, Canoas, 2008. P. 17-26.

MORAIS, Artur G. de. Se a escrita alfabética é um sistema notacional (e não um código), que implicações isto tem para a alfabetização? IN: MORAIS, Artur G. de ALBUQUERQUE, Eliana B. C. de, LEAL, Telma Ferraz (Orgs.) Alfabetização: apropriação do sistema de escrita alfabética. Belo Horizonte: Autêntica, 2005.

PAPALIA, Daiane E.; FELDMAN, Ruth Duskin. Desenvolvimento humano [recurso eletrônico] tradução: Carla Filomena Marques Pinto Vercesi [et al.]; [revisão técnica: Maria Cecília de Vilhena Moraes Silva [et al.] 12. ed. - Dados eletrônicos. - Porto Alegre: AMGH, 2013.

PIAGET, Jean. Problemas de psicologia genética. São Paulo: Abril, I983.

PEDUZZI, Pedro. Mais de $50 \%$ dos alunos do $3^{\circ}$ ano têm nível insuficiente em leitura e matemática. Disponível em:<https://agenciabrasil.ebc.com.br/educacao/noticia/2017-1o/mais-de-5o-dos-alunos-do-3oano-tem-nivel-insuficiente-em-leitura-e> Acesso em o9 de jan. de 2021. Acesso: 25/10/2017.

RIBEIRO, Jair. Única saída para a rede pública é não reprovar ninguém, diz Jair Ribeiro. Disponível em:<https://www.poder36o.com.br/poder-em-foco/unica-saida-para-a-rede-publica-e-nao-reprovarninguem-diz-jair-ribeiro/> Acesso em I3 de jan. de 2021. Acesso em: 21/09/2020.

SANTO, Edeil Reis do Espírito. Os Slogans Construtivistas e os Sentidos da sistematização: Compreensões e distorções Via processo de Formação Docente. 2015

SOARES, Magda. Letramento. Belo Horizonte: Autêntica, 1990.

SOARES, Magda. Linguagem e escola: uma perspectiva social. $8^{\underline{a}}$ ed. São Paulo: Ática, I991. 
SOARES, Magda. Letramento e alfabetização: as muitas facetas. Revista Brasileira de Educação. p. 5-17, 2003.

SOARES, Magda. Letramento: um tema em três gêneros. São Paulo: Autêntica 1999.

TEBEROSKY, Ana e CARDOSO, Beatriz. Reflexões sobre o ensino da leitura e da escrita. 8 ed. Petrópolis: Vozes, 1993.

WEISZ, Telma. Alfabetização no contexto das políticas públicas. Disponível em: 〈http://portal.mec.gov.br/seb/arquivos/pdf/volid.pdf〉 Acesso em: I4 de jan. de 202I. 
Revista Ibero- Americana de Humanidades, Ciências e Educação- REASE

open 2 access 